\title{
Indications and technique for laparoscopic liver resection in patients with hepatocellular carcinoma and liver cirrhosis
}

\author{
Yuichiro Otsuka, Masaru Tsuchiya, Toshio Katagiri, Yoshihisa Kubota, Jun Ishii, Tetsuya Maeda, Hironori Kaneko \\ Division of General and Gastroenterological Surgery, Department of Surgery, Toho University Faculty of Medicine, Tokyo 143-8541, Japan. \\ Correspondence to: Dr. Hironori Kaneko, Division of General and Gastroenterological Surgery, Department of Surgery, Toho University Faculty \\ of Medicine, 6-11-1, Omorinishi, Ota-ku, Tokyo 143-8541, Japan. E-mail: hironori@med.toho-u.ac.jp
}

How to cite this article: Otsuka Y, Tsuchiya M, Katagiri T, Kubota Y, Ishii J, Maeda T, Kaneko H. Indications and technique for laparoscopic liver resection in patients with hepatocellular carcinoma and liver cirrhosis. Hepatoma Res 2016;2:241-7.

\section{Article history: \\ Received: 26-04-2016 \\ Accepted: 12-07-2016 \\ Published: 19-09-2016}

\section{Key words:}

Laparoscopic liver resection, hepatocellular carcinoma, liver cirrhosis

\begin{abstract}
Liver resection is the preferred initial treatment option for solitary or limited multifocal hepatocellular carcinoma (HCC). However, because of the characteristics of HCC, including its high recurrence rate and the frequent presence of chronic hepatitis and cirrhosis, both curability and invasiveness must be considered when selecting a treatment for HCC. Laparoscopic liver resection (LLR) is minimally invasive and increasingly performed worldwide as a curative surgical option for treatment of liver tumors. The 2014 International Consensus Conference on LLR concluded that minor LLRs are now standard practice. Meta-analyses suggest that, as compared with open hepatectomy, LLR for patients with HCC, including those with cirrhosis, resulted in less blood loss, lower postoperative hospitalization rates, and similar oncological outcomes. Although candidates for this procedure should be carefully evaluated, LLR appears to be a feasible option for treatment of HCC with liver cirrhosis. This review describes the indications for LLR in this patient subgroup and offers guidance on appropriate surgical technique.
\end{abstract}

\section{INTRODUCTION}

Hepatocellular carcinoma $(\mathrm{HCC})$ is the sixth most common neoplasm and the third most frequent cause of cancer death in the world. ${ }^{[1]}$ Because of the specific characteristics of $\mathrm{HCC}$, including its high recurrence rate and the frequent presence of chronic hepatitis and cirrhosis, HCC treatment should focus on both curability and invasiveness.

Liver resection is the preferable initial treatment option for solitary or limited multifocal HCCs with no extrahepatic spread. ${ }^{[2-6]}$ The mortality and morbidity of liver resection have significantly decreased in the last two decades because of improvements in patient evaluation, surgical technique, and perioperative care. Resection is the ideal treatment, as it allows for complete removal and pathological confirmation of lesions. However, it is more invasive than other locoregional therapies such as transarterial chemoembolization, tumor ablative therapy, and radiation therapy. ${ }^{[7-10]}$

Laparoscopy has been used extensively and continues to improve as a surgical option. Laparoscopic liver resection

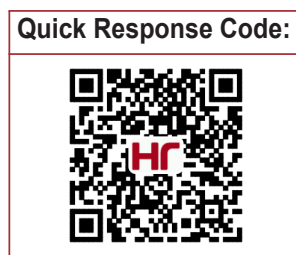


(LLR), a minimally invasive treatment for liver cancer, is now increasingly performed worldwide. ${ }^{[11]}$ However, few studies have investigated LLR for HCC patients with liver cirrhosis, and its applicability for this population is thus unclear. This review describes the indications for LLR in this patient subgroup and offers guidance on appropriate surgical technique.

\section{CURRENT STATUS OF LLR IN THE TREATMENT OF HCC}

LLR was initially described by Reich et al. ${ }^{[12]}$ Subsequent studies showed that it offered minimal invasiveness with no reduction in safety or disease curability for primary and metastatic liver tumors in selected patients. ${ }^{[13,14]}$ However, because of the technical difficulty of this procedure, it was not performed until the 1990s. Development of surgical devices and technical refinements in the early 2000s increased surgical interest. In the First International Consensus Conference (Louisville Consensus), convened in 2008, LLR was described as a safe and effective surgical approach for management of liver disease when performed by trained surgeons with experience in both hepatobiliary and laparoscopic surgery. ${ }^{[15]}$ In addition, a small number of studies reported that LLR was useful for cirrhotic patients. ${ }^{[1,17]}$ With the subsequent uptake of LLR, the Second International Consensus Conference on LLR, held in 2014, concluded that minor LLRs, which were performed for left lateral sectionectomies or resections of anterior and lateral segments (Couinaud's segments II, III, IVb, V, and VI), had become standard practice. ${ }^{[11]}$ Despite encouraging findings from high-volume centers, ${ }^{[18,19]}$ the efficacy of LLR for patients with cirrhosis remains inconclusive because of the low sample sizes of published studies. The most recent meta-analysis indicated that the benefits of LLR would lead to expansion of its indications to include HCC with chronic liver disease. ${ }^{[20]}$

\section{SURGICAL INDICATIONS}

Resection of HCC in patient with liver cirrhosis In patients with HCC with liver cirrhosis, careful selection of surgical candidates is essential in order to avoid treatment-related complications, e.g. liver failure. Because of differences in the characteristics of cirrhosis between Asian and Western countries, there is considerable variability regarding the indications for HCC resection. Therefore, surgical indications for HCC associated with portal hypertension remain controversial. Surgery is contraindicated for patients with encephalopathy, uncontrollable ascites, or jaundice (serum total bilirubin level $>2.0 \mathrm{mg} / \mathrm{dL}$ ). ${ }^{[21]}$

Asian centers have been more aggressive than Western centers in resecting HCC. In Western countries, treatment is driven by the Barcelona Clinic Liver Cancer algorithm, ${ }^{[22,23]}$ in which evidence of portal hypertension is a contraindication for surgical resection. Clinically relevant portal hypertension is defined as the presence of esophageal varices or splenomegaly associated with a platelet count lower than $100 \times 10^{\circ} /$ L. $^{[22]}$

In EastAsian countries, the best candidates for resection are identified by using indocyanine green retention rate as part of a detailed assessment of preoperative hepatic functional reserve. ${ }^{[24,25]}$ Additionally, use of volumetric computed tomography for assessment of remnant liver volume after resection is as important as estimation of hepatic functional reserve. ${ }^{[26]}$ Therefore, patients with signs of portal hypertension can be candidates for resection if they receive adequate perioperative management, e.g. endoscopic treatment of esophageal varices to minimize risk of rupture and pre-hepatectomy or concomitant splenectomy to improve hypersplenism. ${ }^{[21]}$ Anatomic resection, which can remove the tumor-bearing portal territory, is preferred from an oncological perspective for radical treatment of $\mathrm{HCC} .{ }^{[24]}$ Outcomes of liver resection for patients with $\mathrm{HCC}$ and cirrhosis has been dramatically improved with parenchyma-preserving technique. ${ }^{[2]]}$

Percutaneous ablation therapies are another treatment of choice for small nodular HCC in patients with cirrhosis located deep inside the liver; however, such treatment is not suitable for superficially located HCC, because of the increased risk of bleeding, ${ }^{[27]}$ tumor seeding, ${ }^{[28]}$ and thermal injury to adjacent organs. ${ }^{[29]}$ Therefore, surgical resection might be the ideal option for superficial small HCCs.

\section{Patient selection for LLR}

The selection of candidates for LLR is the most important consideration in safely performing LLR. With respect to host factors, an LLR candidate should have liver function sufficient for the same procedure performed as open liver resection. With respect to tumor factors, the classical indications for LLR are that the tumor should have a diameter less than $5 \mathrm{~cm}$ and be located in areas with easy technical access to laparoscopy, i.e. in the left lateral section (Couinaud's segments II and III) or on the surface of the inferior region of the liver (Couinaud's segments $\mathrm{IVb}, \mathrm{V}$, and $\mathrm{VI})$.

Partial liver resection or left lateral sectionectomy are the typical procedures for such tumors. With accumulating experience and technical advancement, LLR has been performed for tumors larger than $5 \mathrm{~cm}$ and for lesions located in the posterior-to-superior region of the liver (Couinaud's segments VII, VIII, and IVa), including advanced non-anatomical and anatomical LLR such as major hepatectomy (involving the abovementioned 

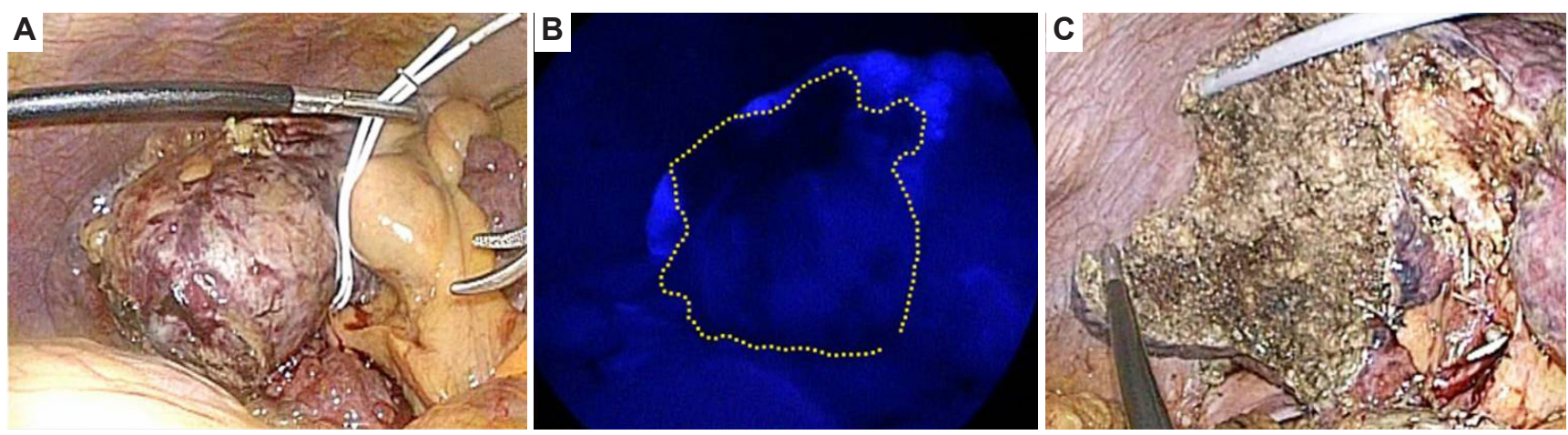

Figure 1: Laparoscopic limited anatomical resection in segment 6 in a patient with hepatocellular carcinoma (HCC) and Child-Pugh class B cirrhosis. (A) HCC and liver cirrhosis in segment 6; (B) illumination by indocyanine green fluorescence imaging shows the inflow preserved area after occlusion of the Glissonean pedicle of segment 6 . Dotted line shows liver transection line; (C) liver resection plane

three Couinaud's segments), at high-volume centers.

In patients with cirrhosis, parenchyma-preserving limited anatomical resection along a demarcation line on the liver surface (formed by division of the Glissonean sheath at the hepatic hilus) is now achievable using laparoscopic technique. A recent modality, laparoscopic near-infrared fluorescence imaging, ${ }^{[30]}$ allows for precise anatomic resection [Figure 1].

LLR has a steep learning curve; therefore, the technical ability of a particular surgical team should be considered when assessing the applicability of LLR. A recent study proposed a difficulty scoring system for stepwise application of LLR, which was based on experience at high-volume Japanese centers. ${ }^{\left[{ }^{[1]}\right.}$ The proposed system predicts surgical difficulty by considering tumor location, extent of liver resection, tumor size, proximity to major vessels, and existing chronic liver damage.

\section{SURGICAL TECHNIQUE FOR LLR}

\section{Patient position and setting}

Under general anesthesia, the patient is positioned depending on the location of the tumor. In general, resection of the left hemi-liver or right anterior region of the liver is performed with the patient in conventional supine position. Resection of the right posterosuperior region of the liver is performed with the patient in a left hemilateral decubitus position, especially for resections requiring mobilization of the right liver from the retroperitoneum. In the left hemilateral position, the patient's body is fixed using a negative pressure bag packed with plastic beads, which is placed under the patient, and several support arms to prevent slipping during abrupt position changes.

The laparoscopic tower contains the light source, camera, and insufflators and is positioned to the right of the patient. Monopolar and bipolar generators for electrocautery devices, a microwave tissue coagulator, and ultrasonically activated devices are placed on the right or left. An ultrasound diagnostic system is also positioned to the left of the patient.

\section{Trocar placement}

After pneumoperitoneum is achieved by means of an umbilical incision, the laparoscope is inserted. For operative manipulation in partial hepatectomy, three or four trocars are placed in a concentric circle radiating from the tumor. In left lateral sectionectomy, three trocars are placed at the right hypochondrium and bilateral abdomen. For anatomical hepatectomies other than left lateral sectionectomy, four trocars are usually necessary: at the epigastrium, right hypochondrium, and bilateral abdomen. Intercostally inserted trocars are useful for manipulation during resection of the superior region of the liver. A 5-mm trocar is placed in the upper abdomen for Pringle's maneuver, when it is needed.

During trocar insertion, surgeons should attempt to preserve collaterals on the abdominal wall in patients with liver cirrhosis. This may require use of ultrasonography to identify collateral vessels. ${ }^{[32]}$

\section{Hepatic parenchymal transection}

For this procedure, laparoscopic ultrasound is performed using a flexible-angle ultrasound probe, to confirm the location of the tumor in relation to the vascular anatomy and identify other lesions in the liver. Although surface roughness from cirrhosis may impede ultrasound inspection, use of a water drip around the ultrasound probe can improve penetration of the ultrasound signal into the liver parenchyma.

Because of the risk of $\mathrm{CO}_{2}$ gas embolism caused by pneumoperitoneum, ${ }^{[3,34]}$ intra-abdominal pressure should be maintained below $8-12 \mathrm{mmHg}$ during the procedure. ${ }^{[35]}$

Chronic liver disease is characterized by significant alterations in the intra- and extrahepatic vasculature. Division of collaterals within the falciform ligament or 
hepatoduodenal ligament, which develop as a result of portal hypertension, should be minimized in the cirrhotic liver.

Parenchymal transection in cirrhotic liver is more hemorrhagic than in non-cirrhotic liver, because of loss of elasticity due to fibrosis and regeneration of liver tissue, the weakness of the altered intrahepatic vasculature, difficulty in identifying intraparenchymal structures, coagulative disorders caused by liver dysfunction, portal hypertension, and hypersplenism. Therefore, reduction of blood loss is a key to successful LLR. Although controversial in laparoscopic surgery, temporary or intermittent application of Pringle's maneuver, use of a vessel tape tourniquet or vessel clamp, can help reduce blood loss during liver parenchymal transection. While performing Pringle's maneuver, surgeons should be careful not to injure collaterals around the hepatoduodenal ligament.

Pre-coagulation technique, in which the resection line is diathermically coagulated using a microwave tissue coagulator or monopolar electrocautery before liver parenchymal transection, can help reduce blood loss in cirrhotic liver. In anatomical hepatectomy, hepatic inflow vessels are isolated with tape traction and occluded before liver parenchymal transection, to identify optimal segmental territory before liver transection. In liver parenchymal transection, laparoscopic coagulating shears are used to divide the superficial layer of the liver. Deeper transection should be performed by meticulously exposing intraparenchymal structures with an ultrasonic surgical aspirator or clamp-crushing technique. Vessels with a diameter of 3-7 $\mathrm{mm}$ are divided with vessel-sealing devices or clips. Then, vessels with a diameter of $2 \mathrm{~mm}$ or less are diathermically sealed using bipolar sealing devices and then divided. Hemostasis of the resection plane is achieved with monopolar or bipolar cautery. A laparoscopic stapler is used to divide major hepatic vessels and for simple transection of liver parenchyma with a thickness of $1-1.5 \mathrm{~cm} .{ }^{[36]}$

LLR is usually performed by pure laparoscopic procedure; however, there are options for a minimally invasive approach. Hand-assisted and laparoscopy-assisted procedures are also occasionally used in technically challenging cases. A hand-assisted procedure is suitable for resection of tumors located in the posterosuperior regions of the liver, to verify tumor margins in the limited operative field and control bleeding. The laparoscopyassisted procedure divides the liver attachment by laparoscopy and transects the liver parenchyma through a small upper abdominal incision under direct vision. It can be used for major hepatectomy or LLR when dense adhesion is present in the abdomen. ${ }^{\left[{ }^{[3]}\right]}$ These approaches may serve as a bridge to pure laparoscopic procedure.
Robot-assisted technique in LLR has been attempted, although the population of patients with liver cirrhosis is quite limited. ${ }^{[38]} A$ recent report suggested that the augmented dexterity and greater range of motion provided by endowristed instruments are helpful, especially in LLR of posterosuperior segments of the liver. ${ }^{[39]}$

\section{Specimen retrieval}

After liver resection is completed, the removed specimen should be placed in a plastic bag, to avoid seeding and implantation of tumor cells in the operative field. Small specimens can be retrieved from a trocar wound made at the umbilical site. Larger specimens are retrieved from an extended umbilical incision, suprapubic incision, or an incision made at an incision site for a previous surgery.

\section{OPERATIVE OUTCOMES OF LLR FOR HCC WITH LIVER CIRRHOSIS}

\section{Short-term outcomes}

Liver resection for $\mathrm{HCC}$ can be performed in some patients with advanced liver disease. Post-hepatectomy morbidity is reported to be high, and long-term prognosis is poor in patients with portal hypertension. ${ }^{[40-42]}$ Such patients might be better served by liver transplantation or ablation. ${ }^{[43]}$ However, some recent studies reported encouraging liver resection outcomes, even in patients with portal hypertension. ${ }^{[21,44,45]}$ Therefore, hepatic resection may be regarded as the primary treatment option for patients with mild portal hypertension, if liver transplantation is not possible.

Systematic reviews and meta-analyses of nonrandomized comparative or case-control studies of HCC suggest that LLR results in less blood loss and shorter postoperative hospital stays ${ }^{[46-49]}$ as compared with open hepatectomy. ${ }^{[50-54]}$ With respect to technical considerations, the reported conversion rate to open surgery for LLR is $0-19.4 \% .{ }^{[49,53,54]}$ Hemorrhage during hepatic parenchymal transection is the most frequent reason for conversion. ${ }^{[49,53,54]}$ To control hemorrhage during liver parenchymal transection, it is essential to select the appropriate surgical devices, including diathermy precoagulation of the resection plane before liver transection. ${ }^{[55]}$

A clear benefit of minimally invasive surgery is that it minimizes abdominal wall trauma. LLR preserves collateral formation in the abdominal wall and thus results in lower incidences of ascites accumulation and postoperative liver failure, as compared with open surgery. ${ }^{[18,51,54]}$ Lessincisional procedures, such as single-port endoscopic surgery, are likely to be less destructive when performed for carefully selected patients. ${ }^{[56]}$

Additionally, repeat hepatectomy for recurrent HCC 
may be indicated, with or without prior local ablation therapy, if abdominal adhesion is limited and tumor location and characteristics are suitable for a laparoscopic approach. ${ }^{[57]}$

\section{Long-term outcomes}

With respect to oncological considerations, evidence from meta-analyses suggests that surgical tumor margins are adequately maintained during LLR. ${ }^{[46,47,50-54]}$ In addition, an analysis of long-term outcomes showed no oncological disadvantage as compared with open liver resection in relation to disease-free or overall survival in metaanalyses of LLR for HCC, especially in well compensated (Child-Pugh class A) liver cirrhosis. ${ }^{[49,51,53]}$

The rate of $\mathrm{HCC}$ recurrence is positively associated with cirrhosis progression; therefore, long-term outcomes of HCC patients with substantial liver cirrhosis (Child-Pugh class $\mathrm{B}$ or $\mathrm{C}$ ) remain poor. Liver transplantation is the most effective treatment for end-stage liver disease and localized malignancy. ${ }^{[58]}$ Current evidence indicates that liver transplantation is the only suitable treatment for HCC in patients with Child-Pugh class C disease. ${ }^{[59]}$ Unfortunately, this optimal procedure is rarely performed because of the severe shortage of donor organs. A study comparing liver resection and liver transplantation for HCC with liver cirrhosis found that liver resection resulted in comparable overall survival in patients with solitary HCC less than $3 \mathrm{~cm}$ and cirrhosis. ${ }^{[58]}$ Interestingly, LLR may be better than open liver resection as a bridge to liver transplantation in patients with superficial HCC accompanied by liver cirrhosis, because of the ability of LLR to control disease while limiting postoperative abdominal adhesion. ${ }^{[60]}$ Because of the necessity of careful maintenance of liver function and oncological control, LLR could play an important role in treating small peripherally located HCC in patients with advanced liver cirrhosis. ${ }^{[1-53]}$ However, the effects of liver resection for HCC on subsequent suitability for liver transplantation are not well clarified.

\section{CONCLUSION}

Existing evidence suggests that LLR is an important alternative treatment option for HCC in patients with substantial liver cirrhosis, although this hypothesis will require further evaluation in future studies. Candidates for this procedure should be carefully evaluated. Use of proper technique would maximize the benefits of LLR and make it an ideal treatment option for this patient subgroup.

\section{Financial support and sponsorship None.}

\section{Conflicts of interest}

There are no conflicts of interest.

\section{Patient consent \\ Not involved.}

\section{Ethics approval}

Not involved.

\section{REFERENCES}

1. Ferlay J, Shin HR, Bray F, Forman D, Mathers C, Parkin DM. Estimates of worldwide burden of cancer in 2008: GLOBOCAN 2008. Int J Cancer 2010;127:2893-917.

2. Forner A, Llovet JM, Bruix J. Hepatocellular carcinoma. Lancet 2012;379:1245-55.

3. Kudo M, Izumi N, Kokudo N, Matsui O, Sakamoto M, Nakashima O, Kojiro M, Makuuchi M. Management of hepatocellular carcinoma in Japan: Consensus-Based Clinical Practice Guidelines proposed by the Japan Society of Hepatology (JSH) 2010 updated version. Dig Dis 2011;29:339-64.

4. European Association For The Study Of The Liver, European Organisation For Research Treatment Of Cancer. EASL-EORTC clinical practice guidelines: management of hepatocellular carcinoma. $J$ Hepatol 2012;56:908-43.

5. Sastre J, Díaz-Beveridge R, García-Foncillas J, Guardeño R, López C, Pazo R, Rodriguez-Salas N, Salgado M, Salud A, Feliu J. Clinical guideline SEOM: hepatocellular carcinoma. Clin Transl Oncol 2015;17:988-95.

6. Korean Liver Cancer Study Group (KLCSG); National Cancer Center, Korea (NCC). 2014 Korean Liver Cancer Study Group-National Cancer Center Korea practice guideline for the management of hepatocellular carcinoma. Korean J Radiol 2015;16:465-522.

7. Capussotti L, Ferrero A, Viganò L, Polastri R, Tabone M. Liver resection for HCC with cirrhosis: surgical perspectives out of EASL/ AASLD guidelines. Eur J Surg Oncol 2009;35:11-5.

8. Hwang S, Lee SG, Belghiti J. Liver transplantation for HCC: its role: Eastern and Western perspectives. J Hepatobiliary Pancreat Sci 2010;17:443-8.

9. Lau WY, Leung TW, Yu SC, Ho SK. Percutaneous local ablative therapy for hepatocellular carcinoma: a review and look into the future. Ann Surg 2003;237:171-9.

10. Li D, Kang J, Golas BJ, Yeung VW, Madoff DC. Minimally invasive local therapies for liver cancer. Cancer Biol Med 2014;11:217-36.

11. Wakabayashi G, Cherqui D, Geller DA, Buell JF, Kaneko H, Han HS, Asbun H, O’Rourke N, Tanabe M, Koffron AJ, Tsung A, Soubrane O, Machado MA, Gayet B, Troisi RI, Pessaux P, Van Dam RM, Scatton O, Abu Hilal M, Belli G, Kwon CH, Edwin B, Choi GH, Aldrighetti LA, Cai X, Cleary S, Chen KH, Schön MR, Sugioka A, Tang CN, Herman P, Pekolj J, Chen XP, Dagher I, Jarnagin W, Yamamoto M, Strong R, Jagannath P, Lo CM, Clavien PA, Kokudo N, Barkun J, Strasberg SM. Recommendations for laparoscopic liver resection: a report from the second international consensus conference held in Morioka. Ann Surg 2015;261:619-29.

12. Reich H, McGlynn F, DeCaprio J, Budin R. Laparoscopic excision of benign liver lesions. Obstet Gynecol 1991;78:956-8.

13. Kaneko H, Takagi S, Shiba T. Laparoscopic partial hepatectomy and left lateral segmentectomy: technique and results of a clinical series. Surgery 1996;120:468-75.

14. Kaneko H, Takagi S, Otsuka Y, Tsuchiya M, Tamura A, Katagiri T, Maeda T, Shiba T. Laparoscopic liver resection of hepatocellular carcinoma. Am J Surg 2005;189:190-4.

15. Buell JF, Cherqui D, Geller DA, O'Rourke N, Iannitti D, Dagher I, Koffron AJ, Thomas M, Gayet B, Han HS, Wakabayashi G, Belli G, 
Kaneko H, Ker CG, Scatton O, Laurent A, Abdalla EK, Chaudhury P, Dutson E, Gamblin C, D’Angelica M, Nagorney D, Testa G, Labow D, Manas D, Poon RT, Nelson H, Martin R, Clary B, Pinson WC, Martinie J, Vauthey JN, Goldstein R, Roayaie S, Barlet D, Espat J, Abecassis M, Rees M, Fong Y, McMasters KM, Broelsch C, Busuttil R, Belghiti J, Strasberg S, Chari RS; World Consensus Conference on Laparoscopic Surgery. The international position on laparoscopic liver surgery: The Louisville Statement, 2008. Ann Surg 2009;250:825-30.

16. Laurent A, Cherqui D, Lesurtel M, Brunetti F, Tayar C, Fagniez PL. Laparoscopic liver resection for subcapsular hepatocellular carcinoma complicating chronic liver disease. Arch Surg 2003;138:763-9.

17. Belli G, Fantini C, D’Agostino A, Cioffi L, Langella S, Russolillo N, Belli A. Laparoscopic versus open liver resection for hepatocellular carcinoma in patients with histologically proven cirrhosis: short- and middle-term results. Surg Endosc 2007;21:2004-11.

18. Morise Z, Sugioka A, Kawabe N, Umemoto S, Nagata H, Ohshima H, Kawase J, Arakawa S, Yoshida R. Pure laparoscopic hepatectomy for hepatocellular carcinoma patients with severe liver cirrhosis. Asian $J$ Endosc Surg 2011;4:143-6.

19. Kanazawa A, Tsukamoto T, Shimizu S, Kodai S, Yamazoe S, Yamamoto S, Kubo S. Impact of laparoscopic liver resection for hepatocellular carcinoma with F4-liver cirrhosis. Surg Endosc 2013;27:2592-7.

20. Morise Z, Ciria R, Cherqui D, Chen KH, Belli G, Wakabayashi G. Can we expand the indications for laparoscopic liver resection? A systematic review and meta-analysis of laparoscopic liver resection for patients with hepatocellular carcinoma and chronic liver disease. $J$ Hepatobiliary Pancreat Sci 2015;22:342-52.

21. Ishizawa $\mathrm{T}$, Hasegawa $\mathrm{K}$, Aoki $\mathrm{T}$, Takahashi M, Inoue $\mathrm{Y}$, Sano K, Imamura H, Sugawara Y, Kokudo N, Makuuchi M. Neither multiple tumors nor portal hypertension are surgical contraindications for hepatocellular carcinoma. Gastroenterology 2008;134:1908-16.

22. Llovet JM, Bru C, Bruix J. Prognosis of hepatocellular carcinoma: the BCLC staging classification. Semin Liver Dis 1999;19:329-38.

23. Bruix J, Sherman M; American Association for the Study of Liver Diseases. Management of hepatocellular carcinoma: an update. Hepatology 2011;53:1020-2.

24. Makuuchi M, Kosuge T, Takayama T, Yamazaki S, Kakazu T, Miyagawa S, Kawasaki S. Surgery for small liver cancers. Semin Surg Oncol 1993;9:298-304.

25. Yim HJ, Suh SJ, Um SH. Current management of hepatocellular carcinoma: an Eastern perspective. World $J$ Gastroenterol 2015;21:3826-42.

26. Yamanaka N, Okamoto E, Oriyama T, Fujimoto J, Furukawa K, Kawamura E, Tanaka T, Tomoda F. A prediction scoring system to select the surgical treatment of liver cancer. Further refinement based on 10 years of use. Ann Surg 1994;219:342-6.

27. Curley SA, Izzo F, Ellis LM, Vauthey NJ, Vallone P. Radiofrequency ablation of hepatocellular cancer in 110 patients with cirrhosis. Ann Surg 2000;232:381-91.

28. Llovet JM, Vilana R, Bru C, Bianchi L, Salmeron JM, Boix L, Ganau $\mathrm{S}$, Sala M, Pagès M, Ayuso C, Solé M, Rodés J, Bruix J; Barcelona Clínic Liver Cancer (BCLC) Group. Increased risk of tumor seeding after percutaneous radiofrequency ablation for single hepatocellular carcinoma. Hepatology 2001;33:1124-9.

29. Teratani T, Yoshida H, Shiina S, Obi S, Sato S, Tateishi R, Mine N, Kondo Y, Kawabe T, Omata M. Radiofrequency ablation for hepatocellular carcinoma in socalled high-risk locations. Hepatology 2006;43:1101-8

30. Otsuka Y, Kaneko H. Usefulness of ICG fluorescence imaging in laparoscopic liver resection. In: Kusano M, Kokudo N, Toi M, Kaibori $\mathrm{M}$, editors. ICG Fluorescence Imaging and Navigation Surgery. Tokyo: Springer Japan; 2016. p. 397-408.

31. Ban D, Tanabe M, Ito H, Otsuka Y, Nitta H, Abe Y, Hasegawa Y, Katagiri T, Takagi C, Itano O, Kaneko H, Wakabayashi G. A novel difficulty scoring system for laparoscopic liver resection. $J$ Hepatobiliary Pancreat Sci 2014;21:745-53.

32. Yeh HC, Stancato-Pasik A, Ramos R, Rabinowitz JG. Paraumbilical venous collateral circulations: color Doppler ultrasound features. $J$ Clin Ultrasound 1996;24:359-66.

33. Takagi S. Hepatic and portal vein blood flow during carbon dioxide pneumoperitoneum forlaparoscopic hepatectomy. Surg Endosc 1998; 12:427-31

34. Min SK, Kim JH, Lee SY. Carbon dioxide and argon gas embolism during laparoscopic hepatic resection. Acta Anaesthesiol Scand 2007;51:949-53

35. Otsuka Y, Katagiri T, Ishii J, Maeda T, Kubota Y, Tamura A, Tsuchiya M, Kaneko H. Gas embolism in laparoscopic hepatectomy: what is the optimal pneumoperitoneal pressure for laparoscopic major hepatectomy? J Hepatobiliary Pancreat Sci 2013;20:137-40.

36. Kaneko H, Otsuka Y, Takagi S, Tsuchiya M, Tamura A, Shiba T Hepatic resection using stapling devices. Am J Surg 2004;187:280-4.

37. Otsuka Y, Tsuchiya M, Maeda T, Katagiri T, Isii J, Tamura A, Yamazaki K, Kubota Y, Suzuki T, Suzuki T, Kagami S, Kaneko H. Laparoscopic hepatectomy for liver tumors: proposals for standardization. $J$ Hepatobiliary Pancreat Surg 2009;16:720-5.

38. Tsung A, Geller DA, Sukato DC, Sabbaghian S, Tohme S, Steel J, Marsh W, Reddy SK, Bartlett DL. Robotic versus laparoscopic hepatectomy: a matched comparison. Ann Surg 2014;259:549-55.

39. Montalti R, Scuderi V, Patriti A, Vivarelli M, Troisi RI. Robotic versus laparoscopic resections of posterosuperior segments of the liver: a propensity score-matched comparison. Surg Endosc 2016;30:100413.

40. Llovet JM, Fuster J, Bruix J. Intention-to-treat analysis of surgical treatment for early hepatocellular carcinoma: resection versus transplantation. Hepatology 1999;30:1434-40.

41. An M, Park JW, Shin JA, Choi JI, Kim TH, Kim SH, Lee WJ, Park SJ, Hong EK, Kim CM. The adverse effect of indirectly diagnosed portal hypertension on the complications and prognosis after hepatic resection of hepatocellular carcinoma. Korean J Hepatol 2006; 12:55361.

42. Choi GH, Park JY, Hwang HK, Kim DH, Kang CM, Choi JS, Park YN, Kim do Y, Ahn SH, Han KH, Chon CY, Lee WJ. Predictive factors for long-term survival in patients with clinically significant portal hypertension following resection of hepatocellular carcinoma. Liver Int 2011;31:485-93.

43. Bruix J, Sherman M; American Association for the Study of Liver Diseases. Management of hepatocellular carcinoma: an update. Hepatology 2011;53:1020-2.

44. Capussotti L, Ferrero A, Viganò L, Muratore A, Polastri R, Bouzari H Portal hypertension: contraindication to liver surgery? World J Surg 2006;30:992-9.

45. Cucchetti A, Ercolani G, Vivarelli M, Cescon M, Ravaioli M, Ramacciato G, Ramacciato G, Grazi GL, Pinna AD. Is portal hypertension a contraindication to hepatic resection? Ann Surg 2009;250:922-8.

46. Simillis C, Constantinides VA, Tekkis PP, Darzi A, Lovegrove R, Jiao $\mathrm{L}$, Antoniou A. Laparoscopic versus open hepatic resections for benign and malignant neoplasms: a meta-analysis. Surgery 2007;141:203-11.

47. Croome KP, Yamashita MH. Laparoscopic vs. open hepatic resection for benign and malignant tumors: an updated meta-analysis. Arch Surg 2010;145:1109-18.

48. Mizuguchi T, Kawamoto M, Meguro M, Shibata T, Nakamura Y, Kimura Y, Furuhata T, Sonoda T, Hirata K. Laparoscopic hepatectomy: a systematic review, meta-analysis, and power analysis. Surg Today 2001;41:39-47.

49. Zhou YM, Shao WY, Zhao YF, Xu DH, Li B. Meta-analysis of laparoscopic versus open resection for hepatocellular carcinoma. Dig Dis Sci 2011;56:1937-43.

50. Mirnezami R, Mirnezami AH, Chandrakumaran K, Abu Hilal M, 
Pearce NW, Primrose JN, Sutcliffe RP. Short- and long-term outcomes after laparoscopic and open hepatic resection: systematic review and meta-analysis. HPB (Oxford) 2011;13:295-308.

51. Fancellu A, Rosman AS, Sanna V, Nigri GR, Zorcolo L, Pisano M, Melis M. Meta-analysis of trials comparing minimally-invasive and open liver resections for hepatocellular carcinoma. J Surg Res 2011;171:e33-45.

52. Li N, Wu YR, Wu B, Lu MQ. Surgical and oncologic outcomes following laparoscopic versus open liver resection for hepatocellular carcinoma: a meta-analysis. Hepatol Res 2012;42:51-9.

53. Yin Z, Fan X, Ye H, Yin D, Wang J. Short- and long-term outcomes after laparoscopic and open hepatectomy for hepatocellular carcinoma: a global systematic review and meta-analysis. Ann Surg Oncol 2013;20:1203-15.

54. Xiong JJ, Altaf K, Javed MA, Huang W, Mukherjee R, Mai G, Sutton R, Liu XB, Hu WM. Meta-analysis of laparoscopic vs. open liver resection for hepatocellular carcinoma. World $J$ Gastroenterol 2012;18:6657-68.

55. Kaneko H, Tsuchiya M, Otsuka Y, Yajima S, Minagawa T, Watanabe M, Tamura A. Laparoscopic hepatectomy for hepatocellular carcinoma in cirrhotic patients. J Hepatobiliary Pancreat Surg 2009;16:433-8.
56. Kaneko H, Otsuka Y. Laparoscopic Hepatectomy of Hepatocellular Carcinoma with Cirrhosis. In: Asbun HJ, Geller DA, editors. American College of Surgeons, Division of Education. ACS Multimedia Atlas of Surgery: Liver Surgery Volume. Woodbury: Ciné-Med, Inc.; 2014. p. 353-70.

57. Tsuchiya M, Otsuka Y, Maeda T, Ishii J, Tamura A, Kaneko H; Efficacy of laparoscopic surgery for recurrent hepatocellular carcinoma. Hepatogastroenterology 2012;59:1333-7.

58. Adam R, Bhangui P, Vibert E, Azoulay D, Pelletier G, Duclos-Vallée JC, Samuel D, Guettier C, Castaing D. Resection or transplantation for early hepatocellular carcinoma in a cirrhotic liver: does size define the best oncological strategy? Ann Surg 2012;256:883-91.

59. Nouso K, Kokudo N, Tanaka M, Kuromatsu R, Nishikawa H, Toyoda H, Oishi N, Kuwaki K, Kusanaga M, Sakaguchi T, Morise Z, Kitai S, Kudo M. Treatment of hepatocellular carcinoma with Child-Pugh C cirrhosis. Oncology 2014;87 Suppl 1:99-103.

60. Cherqui D, Laurent A, Tayar C, Chang S, Van Nhieu JT, Loriau J, Karoui M, Duvoux C, Dhumeaux D, Fagniez PL. Laparoscopic liver resection for peripheral hepatocellular carcinoma in patients with chronic liver disease: midterm results and perspective. Ann Surg 2006;243:499-506. 